ISSN 0103-9954

\title{
PADRÃO E PROCESSO SUCESSIONAIS EM FLORESTAS SECUNDÁRIAS DE DIFERENTES IDADES NA AMAZÔNIA ORIENTAL
}

\section{SUCCESSIONAL PATTERN AND PROCESS IN SECONDARY FORESTS OF DIFFERENT AGES IN THE EASTERN AMAZON}

\author{
Maristela Machado Araújo ${ }^{1}$ Joanna Marie Tucker ${ }^{2}$ Steel Silva Vasconcelos ${ }^{3}$ Daniel Jacob Zarin ${ }^{4}$ \\ Wilson Oliveira ${ }^{5}$ Patrícia Delamônica Sampaio ${ }^{6}$ Lívia Gabrig Rangel-Vasconcelos ${ }^{7}$ \\ Francisco de Assis Oliveira ${ }^{8}$ Roberta de Fatima Rodrigues Coelho ${ }^{9}$ Débora Veiga Aragão ${ }^{5}$ \\ Izildinha Miranda ${ }^{10}$
}

\begin{abstract}
RESUMO
A maioria dos estudos de sucessão em florestas secundárias na Amazônia avalia sítios de diferentes idades, que representam uma cronoseqüência sucessional, em vez de monitorar um único sítio por vários anos pelo inventário contínuo. Este estudo comparou a composição e estrutura florísticas de espécies arbóreas com diâmetro a $1,3 \mathrm{~m}$ de altura $(\mathrm{DAP}) \geq 1 \mathrm{~cm}$, em sítios com 4 e 12 anos na Amazônia Oriental, e avaliou a mortalidade e o recrutamento em ambos os sítios baseados em dados de inventário contínuo durante 4 anos de estudo. As áreas de estudo foram abandonadas após múltiplos ciclos de uso agrícola de $7 \mathrm{a}$ 10 anos, desde $\sim 1940$. Ambos os sítios são dominados pelas espécies arbóreas Lacistema pubescens e Vismia guianensis, com densidade de indivíduos, diâmetro, altura, área basal e riqueza de espécies significativamente maiores no sítio de 12 anos. A densidade de indivíduos, ao longo do tempo, foi crescente no sítio de 4 anos e decrescente no de 12 anos; o diâmetro, a altura e a área basal aumentaram nos dois sítios. No sítio de 4 anos, foi constatada uma taxa de recrutamento líquido crescente entre 2000-2001 e 2001-2002, que diminuiu entre 2002-2003, indicando redução gradual na colonização. No sítio de 12 anos, foi observada alta mortalidade líquida (13 e 11\%), sobretudo nas duas primeiras avaliações, indicando o processo de autodesbaste. A combinação dos métodos de cronoseqüência e inventário contínuo aumenta substancialmente o entendimento do desenvolvimento sucessional.
\end{abstract}

Palavras-chave: Amazônia; cronoseqüência; sucessão florestal; floresta secundária.

\section{ABSTRACT}

Most published studies of secondary forest succession in the Amazon examine stands of different ages that represent a successional chronosequence, rather than monitoring a single stand over the long-term. This study compares floristic composition and structure of tree species with diameter at $1.3 \mathrm{~m}$ height (DBH) $\geq 1 \mathrm{~cm}$ in a 4-year-old and a 12-year-old re-growth stand in the Eastern Amazon, and examines mortality and

1. Engenheira Florestal, Dra., Professora Adjunta do Departamento de Ciências Florestais, Centro de Ciências Rurais, Universidade Federal de Santa Maria, CEP 97105-900, Santa Maria (RS). maristela.araujo@smail.ufsm.br

2. Ecóloga, MSc., Pós-Graduanda, Universidade da Flórida, Gainesville, FL, CEP 32611-0760, Estados Unidos. jmtucker@ufl.edu

3. Engenheiro Agrônomo, MSc., Pesquisador, Embrapa Amazônia Oriental, Tv. Dr. Enéas Pinheiro, s/n, CEP 66095100, Belém (PA). steel@cpatu.embrapa.br

4. Bacharel em História, PhD., Professor Adjunto, Universidade da Flórida, Gainesville, FL, CEP 32611-0760, Estados Unidos. zarin@ufl.edu

5. Engenheiro Florestal, BSc., Assistente de pesquisa, Projeto MANFLORA, Av. Tancredo Neves, s/n., CEP 66.077530, Belém (PA).wilson.oliveira@ufra.edu.br

6. Bióloga, MSc., Universidade da Flórida, Gainesville, FL, CEP 32611-0760, Estados Unidos. psampaio@ufl.edu

7. Engenheira florestal, MSc., Bolsista de pesquisa, Embrapa Amazônia Oriental, Tv. Dr. Enéas Pinheiro, s/n, CEP 66095-100, Belém (PA). lgabrig@amazon.com.br

8. Engenheiro florestal, Dr., Professor Adjunto do Instituto de Ciências Agrícolas , Universidade Federal Rural da Amazônia, Av. Tancredo Neves, s/n., CEP 66.077-530, Belém (PA). francisco.oliveira@ufra.edu.br

9. Engenheira florestal, MSc., Pós-Graduanda, Universidade Federal Rural da Amazônia, CEP 66.077-530, Belém (PA).

10. Engenheira Florestal, Dra ${ }^{\mathrm{a}}$, Professora Adjunta do Instituto Sócio-ambiental e de Recursos Hídricos, Universidade Federal Rural da Amazônia, Av. Tancredo Neves, s/n., CEP 66.077-530, Belém (PA). izildinha.miranda@ufra.edu.br

Recebido para publicação em 26/04/2005 e aceito em 16/11/2005. 
recruitment occurring within both stands based on repeated sampling carried out annually for four years. The study areas were abandoned after multiple agricultural cicles that lasted 7 to 10 years, beginning in $\sim 1940$. Both stands are largely dominated by the same tree species Lacistema pubescens and Vismia guianensis, with significantly higher stem density, diameter, height, basal area and species richness in the 12-year-old stand. In the 4-year-old stand there were measured an increase in annual net recruitment during the first two data collection periods but relatively lower net recruitment during the last evaluation period, indicating on-going but gradually weakening colonization. There were registered a high net mortality during the first two data collection periods in the 12-years-old stand with a relatively lower net mortality during the last evaluation indicating rapid self thinning. When used in combination, the chronosequence and the longitudinal approaches significantly strengthen the understanding of successional development.

Key words: Amazon; chronosequence; forestry succession; secondary forest.

\section{INTRODUÇÃO}

A maioria dos estudos sobre o desenvolvimento de florestas secundárias na Amazônia tem sido conduzida partindo das cronoseqüências sucessionais, representadas por uma série de sítios de diferentes idades, mas com clima, solo, topografia, uso prévio da terra e potencial de colonização, similares (Saldarriaga et al., 1988; Uhl et al., 1988; Moran et al., 1994; Salomão, 1994; Vieira, 1996; Tucker et al., 1998; Almeida, 2000; Steininger, 2000). Os poucos estudos com inventário contínuo, utilizando parcelas permanentes, se referem a estágios iniciais de sucessão vegetal após a abertura de clareiras em florestas maduras (Zwetsloot, 1981; Uhl e Jordan, 1984; Uhl, 1987). Conforme Pickett (1989), estudos que utilizam cronoseqüências e inventários contínuos são complementares, considerando que a cronoseqüência serve como fonte de informações descritivas para geração de hipóteses, as quais podem ser verificadas em comparação com informações obtidas nas parcelas permanentes. Os estudos de cronoseqüência são rápidos, de custo relativamente baixo, e expressam padrões de mudanças na estrutura e composição florísticas que ocorrem durante o desenvolvimento da floresta. Por outro lado, estudos com inventário contínuo revelam processos sucessionais, como mortalidade e recrutamento ao longo do tempo, que não são evidentes nos padrões observados na cronoseqüência, embora necessitem de mais tempo de estudo e apresentem um custo mais elevado.

Assim, apesar de estudos de cronoseqüência dominarem a literatura e possuirem vantagens práticas óbvias, eles também têm limitações significativas, pois, mesmo quando as cronoseqüências são bem selecionadas, é impossível eliminar inteiramente o efeito de variações entre sítios, sobretudo, em relação ao prévio uso da terra. Além disso, a cronoseqüência assume que a variação do clima, entre os anos e tipos de distúrbio, têm impacto uniforme nos sítios de diferentes idades (Pickett, 1989).

$\mathrm{Na}$ Amazônia brasileira, pesquisadores têm utilizado a cronoseqüência para descrever o desenvolvimento estrutural e florístico (Saldarriaga et al., 1988; Moran, et al., 1996; Vieira, 1996; Almeida, 2000; Steininger, 2000) e o efeito da intensidade do uso da terra sobre o acúmulo de biomassa vegetal (Uhl, 1987; Buschbacher et al., 1988; Uhl et al., 1988; Fearnside e Guimarães, 1996; Moran et al., 2000; Steininger, 2000). Esses estudos mostram que plantas invasoras e outras herbáceas, junto com espécies lenhosas pioneiras, dominam no início da sucessão. Após 10 a 20 anos, as espécies pioneiras envelhecem e morrem causando mudanças da dominância por espécies típicas de estágios mais avançados e aumentando gradualmente a diversidade da floresta sucessional.

Estudos sobre a sucessão florestal, com base no inventário contínuo publicado na Amazônia, relatam a elevada ocorrência de espécies de floresta primária (Zwetsloot, 1981; Uhl e Jordan, 1984). Esses estudos indicam que somente os primeiros anos de sucessão são dinâmicos, com intensa invasão inicial de espécies herbáceas e um rápido aumento na densidade de indivíduos, conduzindo ao predomínio de poucas espécies pioneirais lenhosas de vida curta, as quais em poucos anos apresentam elevada mortalidade na área. As publicações com análises de dados em áreas em diferentes estágios de desenvolvimento, provenientes de inventário contínuo, são escassas.

Este artigo enfatiza a complementaridade dos métodos de cronoseqüência e de inventário contínuo (sensu Pickett, 1989) no estudo do desenvolvimento de duas florestas sucessionais e adjacentes na Amazônia Oriental, uma inicialmente com 4 anos e a outra com 12 anos. No estudo são focadas três questões: a) Como 
as florestas de 4 e 12 anos diferem em relação à composição florística e estrutural de espécies arbóreas?; b) Como a mortalidade e sobrevivência de espécies arbóreas diferem nos dois sítios?; e c) De que modo o padrão sucessional inferido pela cronoseqüência concorda com os processos observados com a utilização de inventário contínuo?

\section{MATERIAL E MÉTODOS}

\section{Área de estudo}

As áreas estudadas localizam-se na Estação Experimental de Castanhal, Universidade Federal Rural da Amazônia, próximo à cidade de Castanhal ( $\left.1^{\circ} 19^{\prime} \mathrm{S}, 47^{\circ} 57^{\prime} \mathrm{W}\right)$, Pará. O solo está classificado como Latossolo Amarelo Distrófico - Fase Pedregosa I - Concrecionário Laterítico (Tenório et al., 1999). A área apresenta precipitação média anual de 2000 a $2500 \mathrm{~mm}$, concentrada de dezembro a maio. A média anual da temperatura do ar varia entre 24 e $27^{\circ} \mathrm{C}$ (Martorano \& Pereira, 1993).

A paisagem da região é caracterizada por um mosaico de florestas em diferentes estágios de sucessão, áreas com cultura anual e pastagens degradadas. As áreas estudadas são florestas secundárias desenvolvidas partindo de vários ciclos de derruba e queima da vegetação em pousio e subseqüente cultivo de culturas anuais, o que caracteriza o sistema tradicional de agricultura de subsistência. Conforme relato de moradores locais, as áreas de estudo foram abandonadas após múltiplos ciclos de utilização com pousio, geralmente, de 7 a 10 anos, desde $\sim 1940$.

As capoeiras estudadas são separadas por um ramal de $7 \mathrm{~m}$ de largura que conduz à sede da propriedade. A idade das florestas mencionadas no decorrer do trabalho será aquela referente ao início do estudo em 1999, isto é, "floresta de 12 anos" para a área abandonada em 1987 ( 2 ha) e "floresta de 4 anos" para aquela abandonada em 1995 ( 0,5 ha). A floresta de 4 anos apresenta em seu entorno capoeiras em diferentes estágios de sucessão ( 2 e 8 anos, no início do estudo); a floresta de 12 anos é adjacente a uma mata ciliar em um dos lados e florestas secundárias, em diferentes estágios de desenvolvimento nos demais lados. O primeiro inventário foi concluído em dezembro de 1999 na floresta de 12 anos e julho de 2000 na floresta de 4 anos. Posteriormente, os inventários continuaram sendo realizados anualmente, em julho de 2001, 2002 e 2003.

\section{Composição e estrutura}

A vegetação arbórea foi inventariada em quatro parcelas de $10 \times 10$ m nas florestas de 4 e 12 anos, onde foram medidos indivíduos de espécies arbóreas com diâmetro a $1,3 \mathrm{~m}$ de altura (DAP) $\geq 1 \mathrm{~cm}$. Cada árvore medida foi identificada com plaqueta metálica numerada e identificada por botânico experiente. $\mathrm{O}$ material botânico foi coletado e herborizado no herbário da Embrapa Amazônia Oriental.

Com o objetivo de avaliar as possíveis diferenças entre número de espécies, altura, diâmetro e área basal nas florestas estudadas, foi realizada uma comparação entre os valores médios por parcela, pela análise de variância com dois critérios de classificação (Two-way ANOVA), com medidas repetidas no tempo. A avaliação da densidade de indivíduos das três espécies mais comuns em ambos os sítios foi realizada por análise de variância com um critério de classificação (One-way ANOVA), com medidas repetidas no tempo. Quando necessário, os dados foram transformados em " $l n$ " para que fossem apropriados ao teste. Foram também construídos histogramas de distribuição de diâmetro e altura para cada floresta.

\section{Recrutamento e mortalidade}

O inventário contínuo em 2001, 2002 e 2003, dos indivíduos com DAP $\geq 1 \mathrm{~cm}$, permitiram o cálculo das taxas brutas de recrutamento e mortalidade, e taxa líquida de recrutamento para populações de espécies e para comunidade, conforme segue:

a) Recrutamento Bruto $=R_{n+1} / I_{n}$

b) Mortalidade Bruta $=\mathrm{M}_{\mathrm{n}+1} / \mathrm{I}_{\mathrm{n}}$

c) Recrutamento líquido $=\left(\mathrm{I}_{\mathrm{n}+1}-\mathrm{I}_{\mathrm{n}}\right) / \mathrm{I}_{\mathrm{n}}$

Em que: $R_{n+1}=$ número de novos indivíduos registrados no inventário do ano $n+1 ; I_{n}=$ número total de indivíduos registrados no inventário do ano " $\mathrm{n}$ "; $\mathrm{M}_{\mathrm{n}+1}=$ número de indivíduos presentes no inventário do ano "n" e 
registrados como mortos no inventário " $\mathrm{n}+1$ "; $\mathrm{I}_{\mathrm{n}+1}=$ o número de indivíduos registrados no inventário do ano " $\mathrm{n}+1$ ".

\section{RESULTADOS}

A riqueza de espécies arbóreas na floresta de 4 anos foi, aproximadamente, a metade da floresta de 12 anos ( $\mathrm{p}<0,05$, Tabela 1). Durante o inventário contínuo, o número de espécies arbóreas observadas na floresta de 4 anos variou de 21 a 23 e na floresta de 12 anos de 48 a 51 .

TABELA 1: Densidade de indivíduos, diâmetro, altura, área basal e densidade de espécie (média $\pm \mathrm{SE}$ ) para árvores nas florestas de 4 e 12 anos, observadas em Castanhal, Pará, Brasil. Asteriscos indicam diferença significativa entre os sítios e letras indicam diferença significativa entre os anos em determinado sítio ( $\mathrm{P}<0,05$; Análise de variância Two-way por medidas repetidas).

TABLE 1: Density, diameter at breast height, height, species density and basal area (average \pm SE) for overstory trees in 4-year-old and 12-year-old regrowth stands, measured in Castanhal, Pará, Brazil. Asterisks indicate significant differences between stands date, different letters indicate significant differences between years within a given stand $(\mathrm{P}<0.05$; Two-way repeated measure ANOVA).

\begin{tabular}{|c|c|c|c|c|c|c|c|c|}
\hline & \multicolumn{4}{|c|}{ Floresta de 4 anos } & \multicolumn{4}{|c|}{ Floresta de 12 anos } \\
\hline & 2000 & 2001 & 2002 & 2003 & 1999 & 2001 & 2002 & 2003 \\
\hline $\begin{array}{l}\text { Densidade de } \\
\text { indivíduos }\left(100 \mathrm{~m}^{-2}\right)\end{array}$ & $121 \pm 21^{\mathrm{a}}{ }_{*}$ & $158 \pm 26^{\mathrm{b}}$ & $224 \pm 31^{\mathrm{c}}$ & $248 \pm 30^{c}$ & $231 \pm 41^{\mathrm{a}}{ }_{*}$ & $208 \pm 33^{\mathrm{ab}}$ & $189 \pm 31^{\text {bc }}$ & $180 \pm 29^{c}$ \\
\hline Diâmetro (cm) & $1.3 \pm<0.1^{\mathrm{a}}{ }_{*}$ & $1.5 \pm<0.1^{\mathrm{b}}{ }^{\mathrm{s}}$ & $1.5 \pm<0.1^{\mathrm{b}} *$ & $1.6 \pm<0.1^{\mathrm{b}}{ }^{*}$ & $2.6 \pm 0.2^{\mathrm{a}} *$ & $2.8 \pm 0.2^{b} *$ & $2.9 \pm 0.2^{b} *$ & $2.6 \pm 0,2^{\mathrm{c}}{ }_{*}$ \\
\hline Altura (m) & $2.5 \pm 0.1_{*}^{\mathrm{a}}$ & $2.7 \pm<0.1^{\mathrm{ab}} *$ & $2.7 \pm 0.1^{\mathrm{bc}}{ }_{*}$ & $2.9 \pm 0.1^{\mathrm{c}}{ }_{*}$ & $5.0 \pm 0.2^{\mathrm{a}} *$ & $5.1 \pm 0.2^{\mathrm{ab}}{ }_{*}$ & $5.4 \pm 0.2^{\mathrm{bc}}{ }_{*}$ & $5.5 \pm 0.1^{\mathrm{c}}{ }_{*}$ \\
\hline Área basal $\left(\mathrm{m}^{2} \mathrm{ha}^{-1}\right)$ & $1.7 \pm 0.4_{*}^{\mathrm{a}}$ & $3.3 \pm 0.7^{\mathrm{b}}{ }_{*}$ & $4.6 \pm 0.9^{b c}{ }_{*}$ & $5.7 \pm 1.1^{\mathrm{c}} *$ & $15.3 \pm 0.4^{\mathrm{a}} *$ & $16.6 \pm 0.6^{b} *$ & $17.2 \pm 0.2^{\mathrm{bc}}{ }_{*}$ & $17.5 \pm 0.3^{\mathrm{c}}{ }_{*}$ \\
\hline $\begin{array}{l}\text { Densidade de espécie } \\
\left(100 \mathrm{~m}^{2}\right)\end{array}$ & $11 \pm 1 *$ & $12 \pm 1 *$ & $12 \pm 0.1 *$ & $12 \pm 0.1 *$ & $23 \pm 1 *$ & $24 \pm 1 *$ & $23 \pm 1 *$ & $23 \pm 1 *$ \\
\hline
\end{tabular}

Em relação à densidade de indivíduos em $100 \mathrm{~m}^{2}$, a diferença significativa, entre as florestas de $4 \mathrm{e}$ 12 anos, ocorreu somente no primeiro ano de estudo ( $p<0,05$, Tabela 1$)$. Na floresta de 4 anos, houve aumento significativo da densidade com o decorrer do processo de sucessão, tendendo a estabilização, enquanto na floresta de 12 anos, observou-se o processo contrário, com decréscimo do número de indivíduos ao longo do tempo $(\mathrm{p}<0,05$, Tabela 1$)$.

As espécies arbóreas mais abundantes na floresta de 4 anos foram Lacistema pubescens Mart., Vismia guianensis (Aubl.) Choisy, Banara guianensis Aubl. e Myrcia sylvatica (G. Mey.) DC., representando em média $83 \%$ da comunidade (Tabela 2). Na floresta de 12 anos, L. pubescens, M. sylvatica, $V$. guianensis e Lacistema aggregatum Berg Rusby, representaram em média $65 \%$ da comunidade (Tabela 2).

As três espécies comuns e mais representativas em ambas as florestas (Lacistema pubescens, Vismia guianensis e Myrcia sylvatica) mostraram o mesmo comportamento em relação ao aumento da densidade de indivíduos na floresta de 4 anos e redução na floresta de 12 anos em todas as avaliações. No entanto, as duas primeiras espécies ficaram melhor representadas na floresta de 4 anos, enquanto Myrcia sylvatica se sobressaiu na floresta de 12 anos (Tabela 2). 
TABELA 2: Recrutamento e mortalidade total de árvores (DAP $\geq 1 \mathrm{~cm}$ ) em floresta de 4 anos estudada em julho de 2000 (00), 2001 (01), 2002 (02) e 2003 (03), e floresta de 12 anos estudada em novembro de 1999 (99), julho de 2001, 2002 e 2003, em Castanhal, Pará, Brasil. A área amostral foi $400 \mathrm{~m}^{2}$ em cada floresta. As espécies com abundância relativa menor do que $2 \%$ em qualquer um dos sítios foram agrupadas como "outras espécies".

TABLE 2: Recruitment and mortality for woody stems $\geq 1 \mathrm{~cm} \mathrm{DBH}$ in $400 \mathrm{~m}^{2}$ of 4-year-old regrowth stand at July 2000, 2001, 2002 and 2003; and $400 \mathrm{~m}^{2}$ of 12-year-old regrowth stand at November 1999, July 2001, 2002 and 2003, in Castanhal, Pará, Brazil. Species with relative abundances $<2$ percent in both stands are grouped as "other species."

\begin{tabular}{|c|c|c|c|c|c|c|}
\hline \multirow[t]{2}{*}{ Espécie } & N. de indivíduos & Indivíduos recrutados & \% Recrutamento & Indivíduos mortos & $\%$ Mortalidade & Recrutamento líquido(\%) \\
\hline & $00 / 01 / 02 / 03$ & $00-01 / 01-02 / 02-03$ & $00-01 / 01-02 / 02-03$ & $00-01 / 01-02 / 02-03$ & $00-01 / 01-02 / 02-03$ & $00-01 / 01-02 / 02-03$ \\
\hline \multicolumn{7}{|l|}{ Floresta 4 anos } \\
\hline Lacistema pubescens & $188 / 254 / 375 / 431$ & $76 / 147 / 99$ & $40 / 58 / 26$ & $10 / 26 / 43$ & $5 / 10 / 11$ & $35 / 48 / 15$ \\
\hline Vismia guianensis & $93 / 109 / 147 / 153$ & $17 / 51 / 25$ & $18 / 47 / 17$ & $1 / 13 / 19$ & $1 / 12 / 13$ & $17 / 35 / 4$ \\
\hline Banara guianensis & $67 / 88 / 122 / 123$ & $23 / 40 / 15$ & $34 / 45 / 12$ & $2 / 6 / 14$ & $3 / 7 / 11$ & $31 / 39 / 1$ \\
\hline Myrcia sylvatica & $50 / 69 / 105 / 127$ & $24 / 40 / 28$ & $48 / 58 / 27$ & $5 / 4 / 6$ & $10 / 6 / 6$ & $38 / 52 / 21$ \\
\hline Abarema jupunba & $17 / 17 / 15 / 13$ & $0 / 0 / 0$ & $0 / 0 / 0$ & $0 / 2 / 2$ & $0 / 12 / 13$ & $0 /-12 /-13$ \\
\hline Rollinia exsucca & $12 / 24 / 36 / 39$ & $12 / 16 / 7$ & $100 / 67 / 19$ & $0 / 4 / 4$ & $0 / 17 / 11$ & $100 / 50 / 8$ \\
\hline Casearia arbórea & $11 / 11 / 19 / 19$ & $1 / 8 / 1$ & $9 / 73 / 5$ & $1 / 0 / 1$ & $9 / 0 / 5$ & $0 / 73 / 0$ \\
\hline Lacistema aggregatum & $4 / 7 / 13 / 16$ & $3 / 6 / 4$ & $75 / 86 / 31$ & $0 / 0 / 1$ & $0 / 0 / 8$ & $75 / 86 / 23$ \\
\hline Cupania scrobiculata & $0 / 0 / 0 / 0$ & $0 / 0 / 0$ & $0 / 0 / 0$ & $0 / 0 / 0$ & $0 / 0 / 0$ & $0 / 0 / 0$ \\
\hline Inga rubiginosa & $0 / 0 / 0 / 0$ & $0 / 0 / 0$ & $0 / 0 / 0$ & $0 / 0 / 0$ & $0 / 0 / 0$ & $0 / 0 / 0$ \\
\hline Outras espécies (N=17) & $44 / 54 / 63 / 71$ & $10 / 16 / 14$ & $23 / 30 / 22$ & $0 / 7 / 6$ & $0 / 13 / 10$ & $23 / 17 / 13$ \\
\hline \multirow[t]{2}{*}{ Total } & $486 / 633 / 895 / 992$ & $166 / 324 / 193$ & $34 / 51 / 22$ & $19 / 62 / 96$ & $4 / 10 / 11$ & $30 / 41 / 11$ \\
\hline & $99 / 01 / 02 / 03$ & $99-01 / 01-02 / 02-03$ & $99-01 / 01-02 / 02-03$ & $99-01 / 01-02 / 02-03$ & $99-01 / 01-02 / 02-03$ & $99-01 / 01-02 / 02-03$ \\
\hline \multicolumn{7}{|l|}{ Floresta 12 anos } \\
\hline Lacistema pubescens & $363 / 294 / 245 / 218$ & $5 / 3 / 1$ & $1 / 1 / 0$ & $74 / 52 / 28$ & $20 / 18 / 11$ & $-19 /-17 /-11$ \\
\hline Myrcia sylvatica & $195 / 178 / 168 / 160$ & $4 / 6 / 3$ & $2 / 3 / 2$ & $21 / 16 / 10$ & $11 / 9 / 6$ & $-9 /-6 /-4$ \\
\hline Vismia guianensis & $44 / 37 / 28 / 24$ & $0 / 0 / 0$ & $0 / 0 / 0$ & $7 / 9 / 4$ & $16 / 24 / 14$ & $-16 /-24 /-14$ \\
\hline Lacistema aggregatum & $42 / 41 / 43 / 42$ & $0 / 2 / 0$ & $0 / 5 / 0$ & $1 / 0 / 1$ & $2 / 0 / 2$ & $-2 / 5 /-2$ \\
\hline Cupania scrobiculata & $40 / 40 / 42 / 43$ & $1 / 3 / 1$ & $3 / 8 / 2$ & $1 / 1 / 0$ & $3 / 3 / 0$ & $0 / 5 / 2$ \\
\hline Inga rubiginosa & $33 / 33 / 31 / 29$ & $0 / 0 / 0$ & $0 / 0 / 0$ & $0 / 2 / 2$ & $0 / 6 / 6$ & $0 /-6 /-6$ \\
\hline Rollinia exsucca & $27 / 25 / 19 / 19$ & $0 / 0 / 0$ & $0 / 0 / 0$ & $2 / 6 / 0$ & $7 / 24 / 0$ & $-7 /-24 / 0$ \\
\hline Banara guianensis & $8 / 5 / 5 / 5$ & $0 / 0 / 0$ & $0 / 0 / 0$ & $3 / 0 / 0$ & $37.5 / 0 / 0$ & $-37.5 / 0 / 0$ \\
\hline Casearia arborea & $8 / 6 / 6 / 6$ & $0 / 0 / 0$ & $0 / 0 / 0$ & $2 / 0 / 0$ & $25 / 0 / 0$ & $-25 / 0 / 0$ \\
\hline Abarema jupumba & $0 / 0 / 0 / 0$ & $0 / 0 / 0$ & $0 / 0 / 0$ & $0 / 0 / 0$ & $0 / 0 / 0$ & $0 / 0 / 0$ \\
\hline Outras espécies $(\mathrm{N}=43)$ & $163 / 172 / 170 / 176$ & $19 / 6 / 8$ & $12 / 3 / 5$ & $9 / 8 / 2$ & $6 / 4 / 1$ & $6 /-1 / 4$ \\
\hline Total & $923 / 831 / 757 / 722$ & $29 / 20 / 13$ & $3 / 2 / 2$ & $120 / 94 / 47$ & $13 / 11 / 6$ & $-10 /-9 /-4$ \\
\hline
\end{tabular}

Lacistema pubescens foi a espécie que mais respondeu à sucessão, pois apresentou um aumento significativo na densidade de indivíduos na floresta de 4 anos e redução na floresta de 12 anos, enquanto Myrcia sylvatica e Vismia guianensis apresentaram mudanças menos intensas, em ambos sítios $(\mathrm{p}<0,05$, Figura 1). 


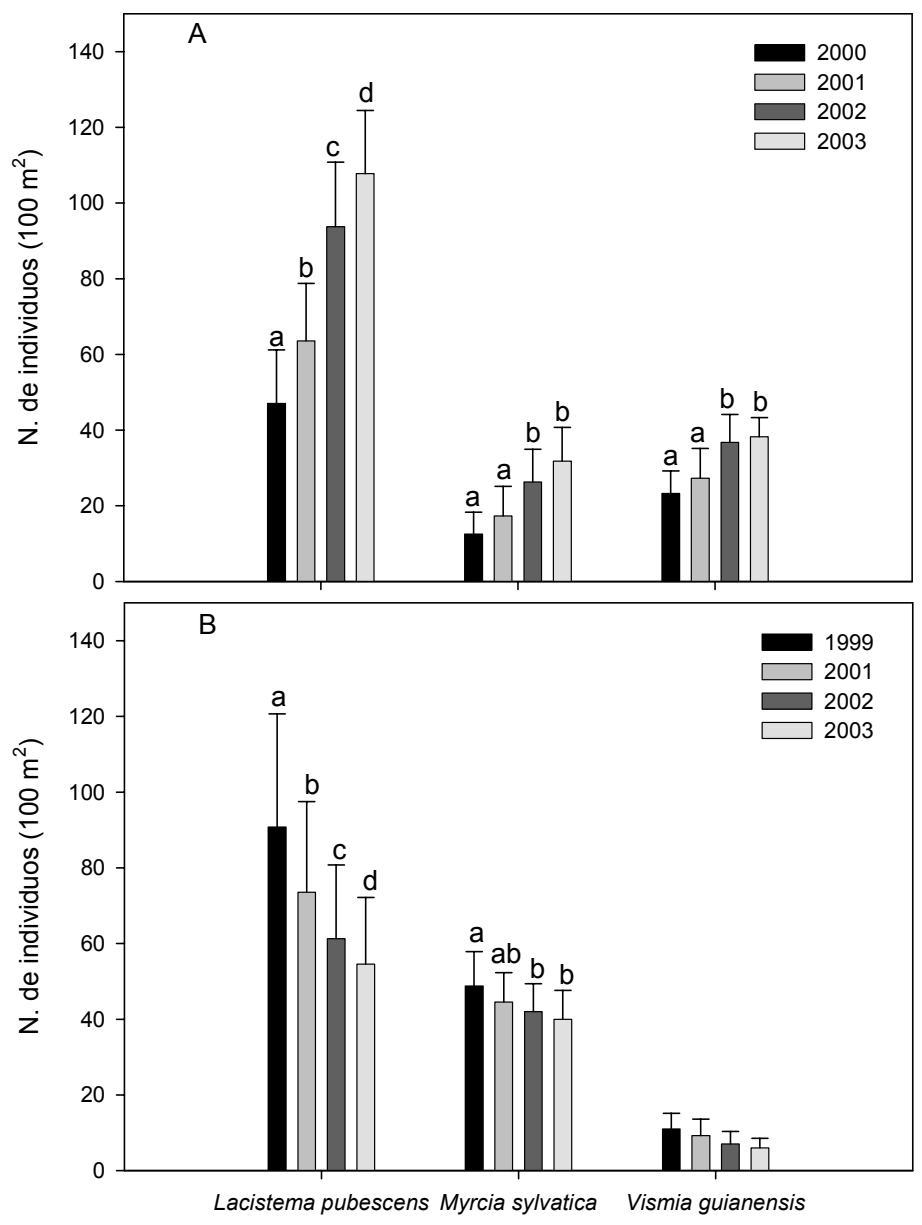

FIGURA 1: Densidade das espécies arbóreas mais comuns na floresta de 4 anos (A) e de 12 anos (B) em Castanhal, Pará, Brasil. Letras diferentes indicam diferença significativa entre os anos $(\mathrm{P}$ $<0.05$, Análise de variância One-Way por medidas repetidas)

FIGURE 1: Densities of three common species in the overstory of 4-year-old (A) and 12-year-old (B) regrowth stands in Castanhal, Pará, Brazil. Different letters indicate significant differences between years $(\mathrm{P}<0.05$; One-way repeated measure ANOVA).

As médias de diâmetro, altura e área basal foram significativamente maiores na floresta de 12 anos em relação a floresta de $4(\mathrm{p}<0,05$, Tabela 1$)$. A floresta do $4^{\circ}$ ao $5^{\circ}$ ano teve incremento significativo em diâmetro (20\%) e área basal (90\%), embora o incremento em altura tenha sido mais gradativo no decorrer da sucessão. Esse mesmo padrão foi observado na floresta de 12 anos ( $<<0,05$, Tabela 1$)$.

As médias de diâmetro e altura médios foram, respectivamente, $1,6 \mathrm{~cm}$ e 2,9 $\mathrm{m}$ na área de 4 anos e $2,9 \mathrm{~cm}$ e $5,5 \mathrm{~m}$ na de 12 anos. A distribuição das classes de diâmetro mostrou-se do tipo "J invertido" e normal nas classes de altura, em ambos os sítios (Figuras 2a1, 2a2 e 3a1, 3a2). No entanto, as três espécies mais comuns nos sítios (Lacistema pubescens, Myrcia sylvatica e Vismia guianensis) mostraram diferentes padrões de distribuição.

Na floresta de 4 anos, Lacistema pubescens apresentou uma maior concentração de indivíduos com DAP entre 1 e $2 \mathrm{~cm}$, enquanto na floresta de 12 anos a maior densidade ocorreu na classe de 2 a $3 \mathrm{~cm}$; quanto à altura, a forma da curva foi semelhante nos dois sítios, embora na floresta de estágio mais avançado ocorra distribuída num maior número de classes (Figuras 2b1, 2b2 e 3b1, 3b2). Em ambas as florestas, a maioria dos indivíduos de Myrcia sylvatica apresentou DAP entre 1 e $2 \mathrm{~cm}$. Em termos de altura, Myrcia sylvatica apresentou a maioria dos indivíduos entre 2 e $4 \mathrm{~m}$, na floresta de 4 anos, atingindo alturas maiores na floresta 
de 12 anos (Figura 2c1, 2c2 e 3c1, 3c2). Na floresta de 4 anos, Vismia guianensis ficou melhor representada por indivíduos com DAP e altura entre 1 e $3 \mathrm{~cm}$, e 3 e $5 \mathrm{~m}$ de altura respectivamente. Na floresta de 12 anos, Vismia guianensis ocorreu em maior número de classes de DAP e altura.
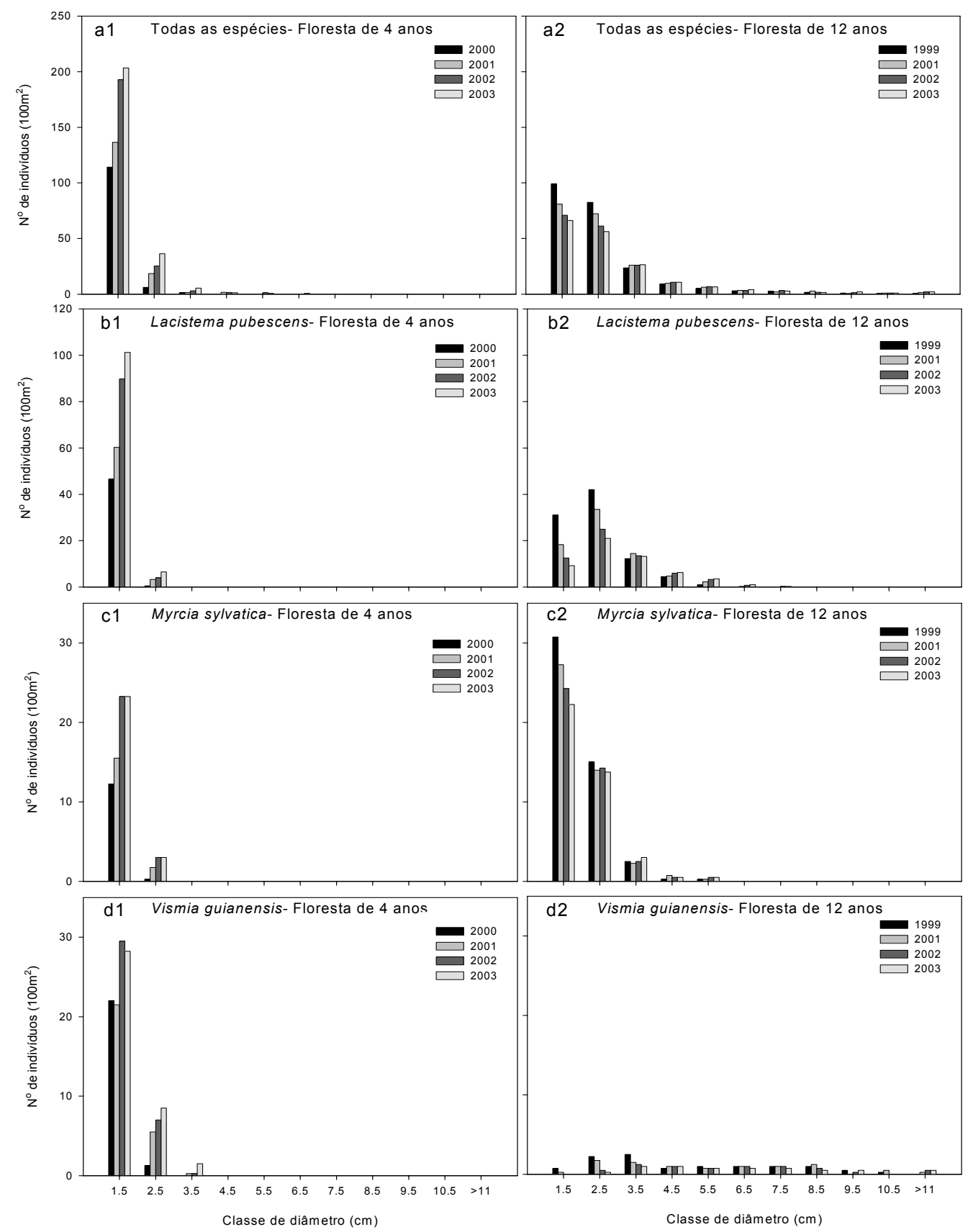

FIGURA 2: Distribuição por classe diamétrica de todas as espécies arbóreas (a), Lacistema pubescens (b), Myrcia sylvatica (c) e Vismia guianensis (d) na floresta de 4 anos (1) e floresta de 12 anos (2) em Castanhal, Pará, Brasil.

FIGURE 2: Overstory diameter class distributions for all woody species (a), Vismia guianensis (b), Lacistema pubescens (c) and Myrcia sylvatica (d) in 4-year-old (1) and 12-year-old (2) regrowth forest stands in Castanhal, Pará, Brazil. 

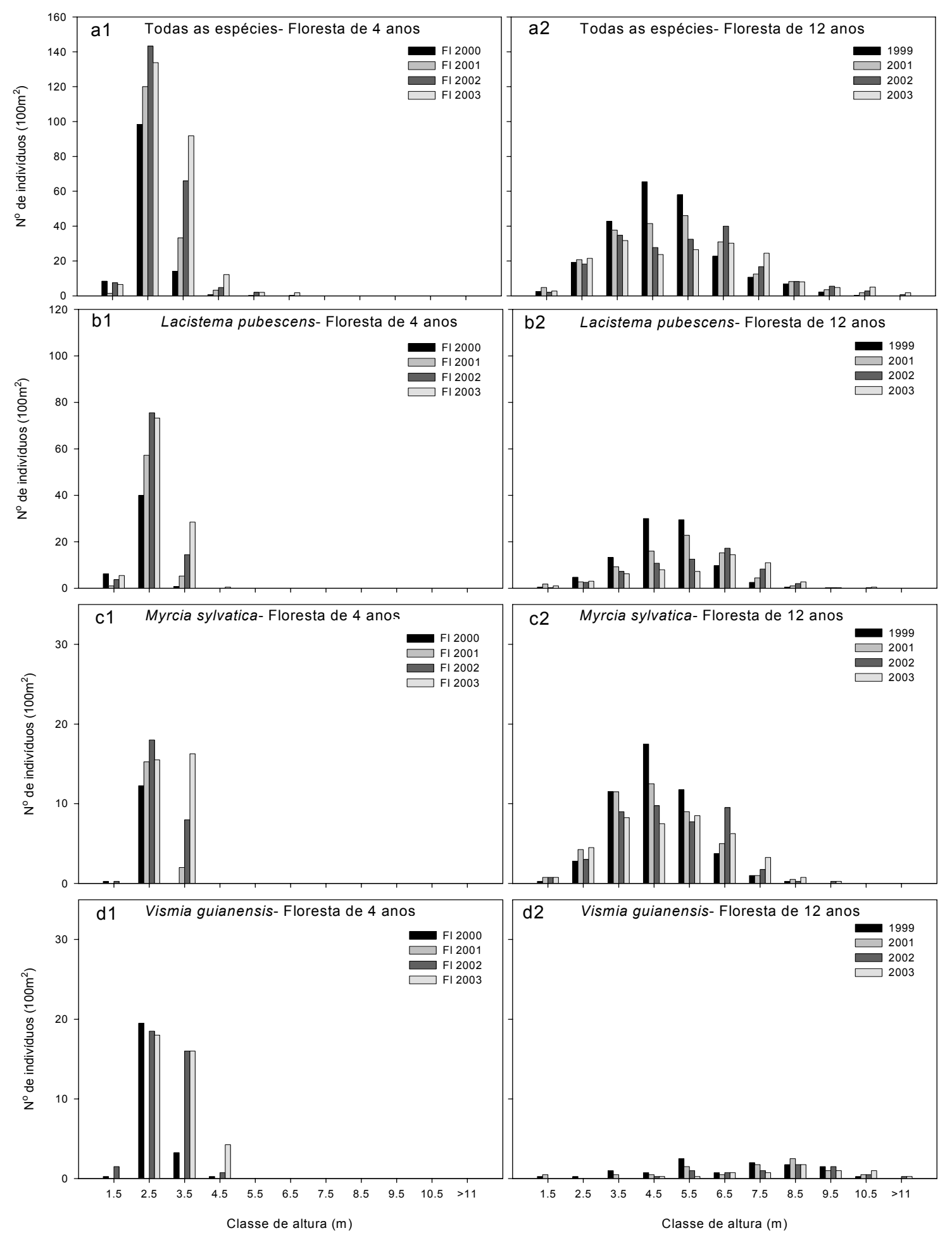

FIGURA 3: Distribuição por classes de altura para todas as espécies arbóreas (a), Lacistema pubescens (b), Myrcia sylvatica (c) e Vismia guianensis (d) na floresta de 4 anos (1) e de 12 anos (2) em Castanhal, Pará, Brasil.

FIGURE 3: Overstory height class distributions for all woody species (a), Vismia guianensis (b), Lacistema pubescens (c) and Myrcia sylvatica (d) in 4-year-old (1) and 12-year-old (2) regrowth stands in Castanhal, Pará, Brazil. 
O recrutamento líquido de indivíduos na floresta de 4 anos nos dois primeiros períodos de estudo, considerando 2000-2001 e 2001-2002, aumentaram 30 e 41\% respectivamente. No terceiro período (2002 a 2003), o recrutamento líquido decresceu para 11\% (Tabela 2). Esta tendência foi observada em todas as parcelas (Tabela 3). A maioria do recrutamento foi por causa das três espécies mais comuns em ambos os sítios (Lacistema pubescens, Vismia guianenesis e Myrcia sylvatica), além de Banara guianensis, as quais apresentaram tendência similar à da comunidade, isto é, de maior recrutamento entre 2000-2002 e menor entre 2002-2003. Abarema jupumba não apresentou recrutamento, e sim $12 \%$ e $13 \%$ de mortalidade, no segundo e terceiro períodos respectivamente. Rollinia exsucca (DC. Ex Dunal) A. DC. e Lacistema aggregatum apresentaram recrutamento líquido positivo, enquanto, Casearia arborea (Rich.) Urb. apresentou um recrutamento líquido de $73 \%$ apenas entre 2001 e 2002; e recrutamento e mortalidade igual nos outros períodos. A maioria das espécies manteve ou aumentou o número de indivíduos e duas espécies novas ingressaram em 2001 e 2002, respectivamente, Connarus angustifolius (Radlkofer) G. Schellend. e Annona paludosa Aubl.

TABELA 3: Recrutamento e mortalidade de árvores em parcelas de $100 \mathrm{~m}^{2}$ na floresta de 4 anos (FS 4) estudada em julho de 2000 (00), 2001 (01), 2002 (02) e 2003 (03), e de 12 anos (FS 12) estudada em novembro de 1999 (99), julho de 2001, 2002 e 2003, em Castanhal, Pará, Brasil.

TABLE 3: Recruitment and mortality of stems $\geq 1 \mathrm{~cm} \mathrm{DBH}$ per $100 \mathrm{~m}^{2}$ plot in the 4-year-old regrowth stand (FS 4) between July 2000 - July 2003; and the 12-year-old regrowth stand (FS 12) between November 1999 - July 2003 in Castanhal, Pará, Brazil.

\begin{tabular}{|c|c|c|c|c|c|c|}
\hline \multirow[t]{2}{*}{ Parcela } & $\begin{array}{l}\text { Número de } \\
\text { indivíduos }\end{array}$ & $\begin{array}{l}\text { Recrutamento } \\
\text { de Indivíduos }\end{array}$ & $\begin{array}{c}\% \\
\text { Recrutamento }\end{array}$ & $\begin{array}{l}\text { Indivíduos } \\
\text { Mortos }\end{array}$ & $\begin{array}{c}\% \\
\text { Mortalidade }\end{array}$ & $\begin{array}{c}\text { Recrutamento } \\
\text { Líquido (\%) }\end{array}$ \\
\hline & $00 / 01 / 02 / 03$ & $00-01 / 01-02 / 02-03$ & $00-01 / 01-02 / 02-03$ & $00-01 / 01-02 / 02-03$ & $00-01 / 01-02 / 02-03$ & $00-01 / 01-02 / 02-03$ \\
\hline \multicolumn{7}{|l|}{ FS 4} \\
\hline 1 & $124 / 185 / 262 / 289$ & $71 / 102 / 65$ & $57 / 55 / 25$ & $10 / 25 / 38$ & $8 / 14 / 15$ & $49 / 42 / 10$ \\
\hline 2 & $67 / 87 / 141 / 173$ & $20 / 58 / 43$ & $30 / 67 / 30$ & $0 / 4 / 11$ & $0 / 5 / 8$ & $30 / 62 / 23$ \\
\hline 3 & $171 / 206 / 278 / 305$ & $40 / 96 / 53$ & $23 / 47 / 19$ & $5 / 24 / 26$ & $3 / 12 / 9$ & $20 / 35 / 10$ \\
\hline 4 & $124 / 155 / 214 / 225$ & $35 / 68 / 32$ & $28 / 44 / 15$ & $4 / 9 / 21$ & $3 / 6 / 10$ & $25 / 38 / 5$ \\
\hline \multirow[t]{2}{*}{ Total } & $486 / 633 / 895 / 992$ & $166 / 324 / 193$ & $34 / 51 / 22$ & $19 / 62 / 96$ & 4/10/11 & $30 / 41 / 11$ \\
\hline & $99 / 01 / 02 / 03$ & $99-01 / 01-02 / 02-03$ & $99-01 / 01-02 / 02-03$ & $99-01 / 01-02 / 02-03$ & $399-01 / 01-02 / 02-03$ & 99-01/01-02/02-03 \\
\hline \multicolumn{7}{|l|}{$\underline{\text { FS } 12}$} \\
\hline 1 & $136 / 134 / 120 / 113$ & $11 / 3 / 2$ & $8 / 2 / 2$ & $13 / 16 / 9$ & $9 / 12 / 8$ & $-1 /-10 /-6$ \\
\hline 6 & $313 / 280 / 252 / 237$ & $5 / 6 / 3$ & $2 / 2 / 1$ & $38 / 34 / 17$ & $12 / 12 / 7$ & $-10 /-10 /-6$ \\
\hline 12 & $192 / 172 / 156 / 152$ & $5 / 2 / 5$ & $3 / 1 / 3$ & $24 / 19 / 9$ & $13 / 11 / 6$ & $-10 /-10 /-3$ \\
\hline 13 & $282 / 245 / 229 / 220$ & $8 / 9 / 3$ & $3 / 4 / 1$ & $45 / 25 / 12$ & $16 / 10 / 5$ & $-13 /-6 /-4$ \\
\hline Total & $923 / 831 / 757 / 722$ & $29 / 20 / 13$ & $3 / 2 / 2$ & $120 / 94 / 47$ & $13 / 11 / 6$ & $-10 /-9 /-4$ \\
\hline
\end{tabular}

Na floresta de 12 anos, a densidade de indivíduos declinou 10, 9 e 4\% de novembro de 1999 a julho de 2001, julho de 2001 a julho de 2002 e deste até julho de 2003, respectivamente (Tabela 2). Da mesma forma, todas as parcelas mostraram maior mortalidade do que recrutamento (Tabela 3). As três espécies mais representativas na floresta de 12 anos (Lacistema pubescens, Myrcia sylvatica e Vismia guianensis) apresentaram maior mortalidade do que recrutamento. Lacistema aggregatum manteve-se, aparentemente, estável no ecossistema, apesar de apresentar recrutamento líquido positivo entre 2001 e 2002 (entre 13 e 14 anos). A maioria dos recrutamentos ocorreu com espécies menos comuns no sítio, como Tabernaemontana angulata Mart. ex. Müll. Arg. e Heisteria sp., além de Lacistema aggregatum e Cupania scrobiculata L.C.Rich., que também tiveram indivíduos ingressados (Tabela 4). Rollinia exsucca apresentaou elevada mortalidade. 
TABELA 4: Espécies lenhosas de florestas secundárias de 4 anos inventariadas $\left(400 \mathrm{~m}^{2}\right)$ em julho de 2000 (00), 2001 (01), $2002(02)$ e $2003(03)$ e de 12 anos inventariadas $\left(400 \mathrm{~m}^{2}\right)$ em novembro de 1999 (99), julho de 2001, 2002 e 2003, em Castanhal, Pará, Brasil.

TABLE 4: Woody species inventory for 4-year-old secondary stand $\left(400 \mathrm{~m}^{2}\right)$, study at July 2000, 2001, 2002 and 2003 and 12-year-old $\left(400 \mathrm{~m}^{2}\right)$, study at November 1999, July 2001, 2002 and 2003, in Castanhal, Pará, Brazil.

\begin{tabular}{|c|c|c|c|c|}
\hline \multirow[t]{3}{*}{ N. } & \multirow[t]{3}{*}{ Família } & \multirow[t]{3}{*}{ Espécie } & \multicolumn{2}{|c|}{ Número de Indivíduos } \\
\hline & & & FS 4 anos & FS 12 anos \\
\hline & & & $00 / 01 / 02 / 03$ & $99 / 01 / 02 / 03$ \\
\hline 1 & Anacardiaceae & Tapirira guianensis Aubl. & 9/9/13/15 & $2 / 2 / 2 / 2$ \\
\hline 2 & Annonaceae & Annona montana Aubl. & $0 / 0 / 0 / 0$ & $3 / 3 / 3 / 3$ \\
\hline 3 & Annonaceae & Annona paludosa Aubl. & $0 / 0 / 1 / 1$ & $11 / 9 / 9 / 9$ \\
\hline 4 & Annonaceae & Guatteria poeppigiana Mart. & $0 / 0 / 0 / 0$ & $2 / 2 / 2 / 2$ \\
\hline 5 & Annonaceae & Rollinia exsucca (DC. ex Dunal) A. DC. & $12 / 24 / 36 / 39$ & $27 / 25 / 19 / 19$ \\
\hline 6 & Annonaceae & Xylopia nitida Duval & $0 / 0 / 0 / 0$ & $1 / 1 / 1 / 1$ \\
\hline 7 & Apocynaceae & Tabernaemontana angulata Mart. ex. Müll.Arg. & $0 / 0 / 0 / 0$ & $6 / 8 / 11 / 11$ \\
\hline 8 & Arecaceae & Astrocaryum munbaca Mart. & $0 / 0 / 0 / 0$ & $4 / 4 / 4 / 4$ \\
\hline 9 & Borraginaceae & Cordia exaltata Lam. & $2 / 2 / 2 / 1$ & $2 / 2 / 2 / 2$ \\
\hline 10 & Burseraceae & Trattinickia burserifolia Mart. & $0 / 0 / 0 / 0$ & $4 / 4 / 3 / 3$ \\
\hline 11 & Clusiaceae & Platonia insignis Mart. & $0 / 0 / 0 / 0$ & $1 / 1 / 1 / 1$ \\
\hline 12 & Clusiaceae & Vismia guianensis (Aubl.) Choisy & $93 / 109 / 147 / 153$ & $44 / 37 / 28 / 24$ \\
\hline 13 & Connaraceae & Connarus angustifolius (Radlkofer) G. Schellend. & $0 / 1 / 1 / 1$ & $6 / 6 / 6 / 6$ \\
\hline 14 & Flacourtiaceae & Banara guianensis Mart. & $67 / 88 / 122 / 123$ & $8 / 5 / 5 / 5$ \\
\hline 15 & Flacourtiaceae & Casearia arborea (Rich.) Urb. & $11 / 11 / 19 / 19$ & $8 / 6 / 6 / 6$ \\
\hline 16 & Flacourtiaceae & Casearia decandra Willd. & $0 / 0 / 0 / 0$ & $1 / 1 / 1 / 1$ \\
\hline 17 & Flacourtiaceae & Casearia javitensis H. B. K. & $0 / 0 / 0 / 0$ & $8 / 9 / 9 / 9$ \\
\hline 18 & Flacourtiaceae & Cecropia palmata Willd. & $1 / 1 / 1 / 1$ & $1 / 1 / 0 / 0$ \\
\hline 19 & Flacourtiaceae & Laetia procera (Poepp.) Eichler & $0 / 0 / 0 / 0$ & $1 / 1 / 1 / 1$ \\
\hline 20 & Lacistemataceae & Lacistema aggregatum (Berg) Rusby & $4 / 7 / 13 / 16$ & $42 / 41 / 43 / 42$ \\
\hline 21 & Lacistemataceae & Lacistema pubescens Mart. & $188 / 254 / 375 / 431$ & $363 / 294 / 245 / 218$ \\
\hline 22 & Lauraceae & Nectandra cuspidata (Mart. ex Nees) Nees & $2 / 7 / 8 / 10$ & $6 / 7 / 4 / 4$ \\
\hline 23 & Lecythidaceae & Couratari cf. oblongifolia Ducke \& Knut. & $0 / 0 / 0 / 0$ & $4 / 4 / 4 / 4$ \\
\hline 24 & Lecythidaceae & Couratari guianensis Aubl. & $0 / 0 / 0 / 0$ & $6 / 6 / 6 / 6$ \\
\hline 25 & Lecythidaceae & Eschweilera sp. & $3 / 3 / 3 / 3$ & $12 / 12 / 12 / 12$ \\
\hline 26 & Melastomataceae & Bellucia grossularioides (L.) Triana & $0 / 0 / 0 / 0$ & $2 / 1 / 1 / 1$ \\
\hline 27 & Melastomataceae & Miconia alata (Aubl.) DC. & $1 / 1 / 2 / 6$ & $0 / 0 / 0 / 0$ \\
\hline 28 & Melastomataceae & Miconia cf. minutiflora & $0 / 0 / 0 / 0$ & $0 / 1 / 1 / 1$ \\
\hline 29 & Melastomataceae & Miconia ciliata Triana & $0 / 0 / 0 / 0$ & $5 / 3 / 2 / 2$ \\
\hline 30 & Melastomataceae & Miconia guianensis Aubl. Cogn & $0 / 0 / 0 / 0$ & $1 / 1 / 1 / 1$ \\
\hline 31 & Melastomataceae & Miconia minutiflora (Bonpl.) DC. & $2 / 2 / 1 / 0$ & $0 / 0 / 0 / 0$ \\
\hline 32 & Melastomataceae & Miconia multiflora Cogn. & $1 / 1 / 0 / 0$ & $0 / 0 / 0 / 0$ \\
\hline 33 & Mimosaceae & Abarema jupunba(Willd.) Britton \& Killip & $17 / 17 / 15 / 13$ & $0 / 0 / 0 / 0$ \\
\hline 34 & Mimosaceae & Inga alba (Sw.) Willd. & $9 / 10 / 11 / 11$ & $0 / 0 / 0 / 0$ \\
\hline
\end{tabular}


TABELA 4: Continuação ...

TABLE 4: Continued ...

\begin{tabular}{|c|c|c|c|c|}
\hline \multirow[t]{3}{*}{$\overline{\mathrm{N}}$. } & \multirow[t]{3}{*}{ Família } & \multirow[t]{3}{*}{ Espécie } & \multicolumn{2}{|c|}{ Número de Indivíduos } \\
\hline & & & FS 4 anos & FS 12 anos \\
\hline & & & $00 / 01 / 02 / 03$ & $99 / 01 / 02 / 03$ \\
\hline 35 & Mimosaceae & Inga auristellae Harnis & $0 / 0 / 0 / 0$ & $2 / 2 / 2 / 2$ \\
\hline 36 & Mimosaceae & Inga flagelliformis (Vell.) Mart. & $6 / 6 / 7 / 8$ & $5 / 5 / 5 / 5$ \\
\hline 37 & Mimosaceae & Inga rubiginosa (Rich.) DC. & $0 / 0 / 0 / 0$ & $33 / 33 / 31 / 29$ \\
\hline 38 & Mimosaceae & Inga stipularis DC. & $0 / 0 / 0 / 0$ & $2 / 1 / 1 / 1$ \\
\hline 39 & Mimosaceae & Inga thibaudiana DC. & $5 / 5 / 10 / 11$ & $11 / 11 / 11 / 12$ \\
\hline 40 & Mimosaceae & Stryphnodendron pulcherrirum Hochr. & $0 / 0 / 0 / 0$ & $8 / 7 / 8 / 8$ \\
\hline 41 & Moraceae & Brosimum guianense (Aubl.) Huber & $0 / 0 / 0 / 0$ & $1 / 1 / 1 / 1$ \\
\hline 42 & Myrtaceae & Eugenia patrisii Vahl. & $0 / 0 / 0 / 0$ & $0 / 2 / 3 / 3$ \\
\hline 43 & Myrtaceae & Myrcia bracteata (Rich.) DC. & $2 / 4 / 2 / 2$ & $6 / 8 / 7 / 6$ \\
\hline 44 & Myrtaceae & Myrcia sylvatica (G. Mey.) DC. & $50 / 69 / 105 / 127$ & $195 / 178 / 168 / 160$ \\
\hline 45 & Myrtaceae & Myrciaria floribunda (West ex Willd.) O. Berg. & $0 / 0 / 0 / 0$ & $2 / 2 / 2 / 2$ \\
\hline 46 & Nyctaginaceae & Neea glomeruliflora Heimerl & $0 / 0 / 0 / 0$ & $3 / 3 / 3 / 4$ \\
\hline 47 & Nyctaginaceae & Neea oppositifolia Ruiz \& Pav. & $0 / 0 / 0 / 0$ & $1 / 3 / 3 / 3$ \\
\hline 48 & Olacaceae & Heisteria sessilis Ducke & $0 / 0 / 0 / 0$ & $2 / 5 / 4 / 3$ \\
\hline 49 & Olacaceae & Heisteria sp. & $0 / 0 / 0 / 0$ & $14 / 15 / 16 / 21$ \\
\hline 50 & Quiinaceae & Lacunaria jenmani (Oliv.) Ducke & $0 / 0 / 0 / 0$ & $2 / 2 / 2 / 2$ \\
\hline 51 & Rubiaceae & Chimarris turbinate DC. & $1 / 1 / 1 / 1$ & $10 / 10 / 10 / 10$ \\
\hline 52 & Rutaceae & Zanthoxylum rhoifolium Lam. & $0 / 0 / 0 / 0$ & $1 / 0 / 0 / 0$ \\
\hline 53 & Sapindaceae & Cupania scrobiculata L.C.Rich. & $0 / 0 / 0 / 0$ & $40 / 40 / 42 / 43$ \\
\hline 54 & Sapindaceae & Talisia $\mathrm{sp}$ & $0 / 0 / 0 / 0$ & $3 / 3 / 3 / 3$ \\
\hline 55 & Siparunaceae & Siparuma guianensis Aubl. & $0 / 0 / 0 / 0$ & $1 / 1 / 1 / 1$ \\
\hline 56 & Vochysiaceae & Vochysia inundata Ducke & $0 / 0 / 0 / 0$ & $0 / 2 / 2 / 2$ \\
\hline 57 & & NI 4 & $0 / 1 / 0 / 0$ & $0 / 0 / 0 / 0$ \\
\hline 58 & & NI 12 & $0 / 0 / 0 / 0$ & $0 / 0 / 0 / 1$ \\
\hline
\end{tabular}

Total

$486 / 633 / 895 / 992 \quad 923 / 831 / 757 / 722$

\section{DISCUSSÃO}

Na Amazônia, Uhl et al. (1988), Vieira (1996) e Peña-Claros (2003) observaram que na sucessão inicial da floresta poucas espécies predominam no ambiente. Entretando, o reduzido número de espécies e a alta densidade de indivíduos na floresta de 12 anos não são comuns quando comparadas com estudos de Vieira (1996) e Almeida (2000) em florestas com idade semelhante na região, embora, Saldarriaga et al. (1988) tenham verificado densidade de indivíduos quatro vezes menor do que foi observado neste estudo. A elevada dominância de espécies na floresta de 12 anos pode ser explicada pela intensidade de uso da terra, a qual se caracterizou por longos e repetidos ciclos de cultivo, durante cerca de 60 anos. Provavelmente, esse intenso uso da terra tenha resultado em esgotamento do banco de sementes do solo e redução da chuva de sementes na área. Sob essas condições, a rebrotação tem uma importante função no restabelecimento dessas florestas na região (Vieira, 1996), portanto, a dominância de Lacistema pubescens, Vismia guianensis, Myrcia sylvatica e Banara guianensis observada neste estudo pode ser atribuída à elevada capacidade de rebrotação dessas espécies. Depois de estabelecidas, tais espécies pioneiras, provavelmente, mantêm sua população por reproduzirem cedo, concordando com os resultados obtidos por Salomão (1994). 
A baixa riqueza florística na floresta de 4 anos durante todo o período de estudo, quando comparada com a floresta de 12 anos, foi uma incógnita, conduzindo à dúvida se seria possível, no intervalo nãoestudado (8 a 11 anos), que o número de espécie aumentasse mais do que o dobro. De acordo com Jacquemyn et al. (2003) o aumento da riqueza de espécies em fragmentos ocorre de acordo com seu grau de isolamento e, apesar da floresta de 4 anos apresentar florestas secundárias no seu entorno, estas também estão em estágio inicial de sucessão, tendo sido submetidas a vários ciclos de cultivo e possível perda de diversidade. Uma hipótese a ser testada é se a floresta ripária e madura, adjacente à floresta de 12 anos, contribuiu para o aumento do número de espécies nesse ecossistema.

Em termos de estrutura, a variação no limite mínimo de diâmetro das árvores amostradas, nos diferentes inventários realizados na Amazônia, dificulta uma análise comparativa dos estudos. Assim, para facilitar a comparação de estudos similares com o presente, foi feita uma separação dos indivíduos com DAP $\geq 5 \mathrm{~cm}$ inventariados neste estudo. Na floresta de 4 anos, as árvores com DAP $\geq 5 \mathrm{~cm}$ só foram observadas a partir do $6^{\circ}$ ano de sucessão, indicando crescimento relativamente menor quando comparado com outros sítios de semelhante idade (Salomão, 1994; Vieira, 1996; Mesquita et al., 2001). Na floresta de 12 anos,

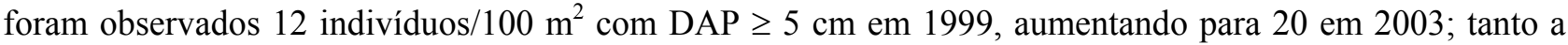
densidade quanto a área basal foram baixas quando comparadas a outros sítios, também de semelhante idade (Salomão, 1994; Vieira, 1996, Mesquita et al., 2001), provavelmente, em conseqüência da baixa fertilidade do solo associada ao intenso uso da terra.

Algumas novas espécies (DAP $\geq 1 \mathrm{~cm}$ ), presentes na floresta de 12 anos e ausentes na floresta de 4 anos como, por exemplo, Cupania scrobiculata, Guatteria poeppigiana Mart. e Inga rubiginosa, são tolerantes à sombra e, conseqüentemente, apresentam um estabelecimento mais tardio. Espécies de floresta madura tanto de terra firme, como de ambiente com maior influência do lençol freático, também estão presentes no sítio de 12 anos, incluindo Trattinickia burserifolia e Vochysia inundata (Almeida, 2000). Embora as espécies pioneiras continuem dominando a vegetação, a presença de muitas espécies tardias na floresta de 12 anos indica uma fase de transição do desenvolvimento sucessional. Outras cronoseqüências sugerem semelhante transição (Saldarriaga et al. 1988; Almeida 2000; Vieira 1996) e são consistentes com o modelo de tolerância sucessional (Connell e Slatyer 1977), onde grupos de espécies se misturam à medida que o desenvolvimento da floresta ocorre, causando uma mudança gradual na dominância e eventual substituição de espécies. A exclusão de Banara guianensis, Casearia arborea e Abarema jupumba na floresta de 12 anos também evidencia o processo de sucessão florestal, onde novas espécies mais tolerantes à sombra passam a competir com as pioneiras e substituí-las.

A Myrcia sylvatica, por exemplo, é uma espécie mais tolerante à sombra que dominou o sub-bosque em ambos os sítios, enquanto a densidade de Vismia guianensis e Banara guianensis (pioneiras intolerantes à sombra) reduziu consideravelmente no sub-bosque do sítio de 12 anos. Com o processo sucessional, Vismia guianensis e Banara guianensis são substituídas por espécies mais tolerantes à sombra como Ocotea costulata, Myrcia bracteata e Miconia ciliata (Lima, 2003; Coelho et al., 2002). Em adição aos padrões sucessionais evidentes nos dados do sub-bosque, a distribuição da população de indivíduos das espécies comuns no dossel, nas florestas de 4 e 12 anos, também revela uma trajetória distinta (Figura 2 e 3 ). A distribuição do diâmetro de Vismia guianensis, Lacistema pubescens e Myrcia sylvatica na floresta de 4 anos foi quase-idêntica. No entanto, a redução da densidade de indivíduos de Vismia guianensis na floresta de 12 anos, em comparação com a de 4 anos, concorda com alguns trabalhos que relatam que Vismia spp., normalmente, persiste 10 a 20 anos após abandono de área agrícolas em outros sítios na Amazônia Oriental (Salomão, 1994) e no Alto Rio Negro (Uhl, 1987).

Quando comparado à floresta de 4 anos, a redução da densidade de indivíduos de Lacistema pubescens na classe de diâmetro pequeno, na floresta de 12 anos, reflete no reduzido recrutamento para os estratos superiores, sugerindo que essa espécie, no decorrer da sucessão, apresentará comportamento similar ao de Vismia guianensis. Em contraste com o comportamento de Lacistema pubescens e Vismia guianensis, a concentração de indivíduos de Myrcia sylvatica na classe de tamanho menor, em ambas as florestas, indica o lento crescimento, porém, numa população mais persistente no processo sucessional.

Lacistema pubescens, Vismia guianensis e Myrcia sylvatica são responsáveis pela maioria das mudanças sucessionais em ambos os sítios, porém os padrões de recrutamento e mortalidade nos dois 
ambientes revelam dois diferentes estágios de desenvolvimento, cada um sujeito a diferente dinâmica. A floresta de 4 anos é um exemplo de sítio inicial dominado por espécies pioneiras, enquanto que a floresta de 12 anos representa um estágio de exclusão de indivíduos estabelecidos e inclusão de novas espécies mais tolerantes nas classes de menor diâmetro (sensu Oliver e Larson 1996).

Os anos iniciais de sucessão secundária na Amazônia são caracterizados por agressivo crescimento da floresta. A elevada disponibilidade de luz durante os anos iniciais de sucessão secundária favorece a germinação, brotação e crescimento de espécies pioneiras (Uhl e Jordan, 1984; Saldarriaga et al., 1988). Na floresta de 4 anos, o recrutamento líquido de 30, 41 e 11\% nos períodos de 2000 a 2001, 2001 a 2002 e 2002 a 2003 respectivamente demonstra a colonização de espécies pioneiras de crescimento agressivo. As quatro espécies mais comuns no sítio, Lacistema pubescens, Vismia guianensis, Banara guianensis e Myrcia sylvatica, representaram em média $83 \%$ de todos indivíduos recrutados e $86 \%$ de todos indivíduos mortos na floresta de 4 anos durante os 36 meses de mensuração.

$\mathrm{Na}$ floresta de 12 anos quase-todas as espécies comuns às duas florestas reduziram sua densidade e aumentaram a porcentagem de mortalidade durante quase todo o período de avaliação, indicando o declínio gradual das pioneiras dominantes (Tabela 2). Esse declínio, provavelmente ocorreu por causa da senescência natural e condições de sombra estabelecida que diminuiram a capacidade de recrutamento (Whitmore, 1990). As três espécies mais comuns no sítio (Lacistema pubescens, Myrcia sylvatica e Vismia guianensis) representaram em média $85 \%$ da mortalidade no período de estudo somente $36 \%$ dos indivíduos recrutados.

As taxas de mortalidade (6-13\%) na floresta de 12 anos são superiores àquelas normalmente registradas para florestas tropicais úmidas em desenvolvimento (1 a 2\%) (Condit et al. 1995; Swaine et al., 1987). No entanto, Condit et al. (1995) também registraram mortalidade anual de espécies colonizadoras superior a 10\% na floresta do Barro Colorado. Em San Carlo do Rio Negro, Uhl e Jordan (1984) registraram mortalidade em massa de Cecropia ficifolia Warb. ex Snethl., depois de dois anos de crescimento.

A comparação da estrutura e composição florísticas das florestas de 4 e 12 anos, tanto na cronoseqüencia como no inventário contínuo, revelou dois sítios dominados por espécies semelhantes. Entre as espécies presentes na floresta de 4 e 12 anos, $46 \%$ e $36 \%$ respectivamente estão presentes em sítios de idade semelhante na região estudados por Vieira (1996).

Quando utilizamos apenas a cronoseqüência não é possível avaliar a real performance das espécies nos ecossistemas como, por exemplo, quando estas começam a ser excluídas, além disso se as florestas de $4 \mathrm{e}$ 12 anos fossem comparadas partindo de dados de um único inventário, acreditar-se-ia que a riqueza florística aumentaria gradativamente, ao longo do processo sucessional e mais do que dobraria o número de espécies aos 12 anos de idade. O inventário contínuo induziu à dúvida se isso irá acontecer por causa da falta de mudanças até o $7^{\circ}$ ano. Nesse sentido, o inventário contínuo é que definiu melhor quando a substituição iniciou e as novas espécies apareceram, complementando o entendimento da auto-ecologia das espécies secundárias. Por outro lado, se a análise for limitada ao inventário contínuo em apenas um dos sítios, os dados de mortalidade e recrutamento não revelam as diferenças de composição e estrutura florística entre os dois sítios.

Os resultados deste estudo indicam que os métodos de cronoseqüência e o inventário contínuo fortalecem o entendimento do desenvolvimento sucessional em florestas quando analisados conjuntamente. No entanto, quando utilizados separadamente, cada abordagem tem sua desvantagem com relação a onerar os custos, requerer mais tempo de avaliação e não perceber ou interpretar incorretamente informações importantes. Quando combinadas, uma abordagem compensa a deficiência da outra.

\section{CONCLUSÕES}

As espécies predominantes foram as mesmas nos sítios de 4 e 12 anos.

Estruturalmente, o autodesbaste inicia próximo aos 12 anos, com redução da densidade.

A floresta de 4 anos representa o estágio de iniciação da floresta, com elevado recrutamento líquido de espécies predominantes; o processo de exclusão predomina na floresta de 12 anos, em conseqüência da elevada mortalidade. 
Os padrões e processos sucessionais são melhores descritos quando se utilizam, conjuntamente, os métodos de cronoseqüência e de inventário contínuo.

\section{AGRADECIMENTOS}

Os autores agradecem a colaboração de Raimundo Nonato da Silva pelo suporte logístico; Alexandre Modesto, Cesar Tenório, Gilson da Silva Sousa, Glebson A. da Silva Sousa, Osório L. Oliveira, Evandro Rodrigues da Silva e Elisângela Santos pela assistência no trabalho de campo. Esta pesquisa foi apoiada pela Estação Experimental de Agricultura da Flórida e financiada pela Fundação Andrew Mellon.

\section{REFERÊNCIAS BIBLIOGRÁFICAS}

AIDE, T. M.; CAVELIER, J. Barriers to lowland tropical forest restoration in the Sierra Nevada de Santa Marta, Colombia. Restoration Ecology, v. 2, p. 219-229, 1994.

ALMEIDA, A. S. Dinâmica da paisagem e ecologia de Florestas Primárias Remanescentes e Sucessionais do Município de São Francisco do Pará. 2000. 100p. Dissertação (Mestrado em Ciências Florestais) - Faculdade de Ciências Agrárias do Pará, 2000.

BUSCHBACHER, R.; UHL, C.; SERRÃO, E. A. S Abandoned Pastures in Eastern Amazonia. II. Nutrient Stocks in the Soil and Vegetation. Journal of Ecology , 76, p. 682-699, 1988

Chapin, F. S. III; Matson, P. A.; Mooney H. A. Principles of terrestrial ecosystem ecology. New York: SpringerVerlag, 2002. 436p.

COELHO, R. de F. R. Análise florística e estrutural de uma floresta em diferentes estágios sucessionais no município de Castanhal, Pará. 2002. 48p. Dissertação (Mestrado em Ciências Florestais) - Universidade Federal Rural da Amazônia, Belém, 2002.

CONDIT, R.; HUBBELL, S. P.; FOSTER, R. B. Mortality rates of 205 neotropical tree and shrub species and the impact of a severe drought. Ecological Monographs, v. 65, n. 4, p. 419-439, 1995.

CONDIT, R.; HUBBELL, S. P.; FOSTER, R. B. Predicting populations trends from size distributions: a direct test in a tropical tree community. American Naturalist, v. 152, n. 4, p. 495-509, 1998.

CONNELL, J. M.; SLATYER, R.O. Mechanisms of succession in natural communities and their role in community stability and organization. American Naturalist, v. 111, p. 1119-1144, 1977.

DENICH, M. Composição florística de capoeiras baixas no município de Igarapé-Açu no Estado do Pará. Belém: EMBRAPA-CPATU, 1986. 16p. (Documentos, 39)

DENICH, M. Estudo da Importância de uma Vegetação Secundária Nova para o Incremento da Produtividade do Sistema de Produção na Amazônia Oriental Brasileira. 284p. Thesis (Ph.D) - University of Georg August of Gottingen. Germany, 1991.

FEARNSIDE, P. M.;GUIMARÃES, W. M. Carbon uptake by secondary forests in Brazilian Amazonia. Forest Ecology and Management, n. 80, p. 35-46, 1996.

FINEGAN, B. Pattern and process in neotropical secondary rain forests: the first 100 years of succession. Tree, v.11, n.3, p.119-124, 1996.

JACQUEMYN, H.; BUTAYE, J.; HERMY, M.. Impacts of reforested patch density and distance from natural forests on colonization success. Restoration Ecology, v.11, n. 4, p. 417-423,2003

LIMA, C. A. T. Regeneração natural de uma floresta secundária sob manipulação de água e nutrientes no município de Castanhal, Pará. 2003. 59p. Dissertação (Mestrado em Ciências Florestais) - Universidade Federal Rural da Amazônia, Belém, 2003.

MARTORANO, L. G.; PEREIRA, L. Estudos climáticos do Estado do Pará, classificação climática (Köppen) e deficiência hídrica (Thornthwaite). SUDAM/EMBRAPA, 1993. 74p.

MESQUITA, R. C. G.; ICKES, K.; GANADE, G.; WILLIAMSON, G. B. Alternative successional pathways in the Amazon Basin. Journal of Ecology, n. 89, p. 528-537, 2001.

MORAN, E. F.; BRONDIZIO, E.; MAUSEL, P.; WU, Y. Integrating Amazonian vegetation, land-use, and satellite data. BioScience, n. 44, p. 329-338, 1994.

MORAN, E. F.; PACKER, A.; BRONDIZIO, E.; TUCKER, J. M. Restoration of vegetation cover in the eastern Amazon. Ecological Economics, n. 18, p. 41-54, 1996. 
MORAN, E. F.; BRONDIZIO, E. S.; TUCKER, J. M.; SILVA-FORSBERG, M. C. DA; MCCRACKEN, S.; FALESI, I. Effects of soil fertility and land-use on forest succession in Amazônia. Forest Ecology and Management, n. 139, p.93-108, 2000.

OLIVER, C. D.; LARSON, B. C. Forest Stand Dynamics. New York: John Wiley \& Sons, 1996. 520p.

PANTOJA, F. B. C.; OLIVERIA, V. C. de; COSTA, L. G. S. ; VASCONCELOS, P. C. S. Estrutura de um trecho de floresta secundária de terra firme, no Município de Benevides, Pará. Belém: FCAP, 1997. (Informe Técnico, 24)

PEÑA-CLAROS, M. Changes in forest structure and species composition during secondary forest succession in Bolivian Amazon. Biotropica, v. 35, n. 4, p. 450-461, 2003.

PICKETT, S. T. A. Space-for-Time Substitution as an Alternative to Long-Term Studies. In : LIKENS,G. E. (Ed.). Long-term Studies in Ecology. New York: Springer-Verlag, 1989. p. 110-135.

SALOMÃO, R. P. Estimativas de biomassa e avalição do estoque de carbono da vegetação de florestas primárias e secundárias de diversas idades (capoeiras) na Amazônia oriental, Municipio de Peixe-Boi, Pará. 1994. 96p. Dissertação (Mestrado em Biologia) - Universidade Federal do Pará, Belém, 1994.

SALDARRIAGA, J. G.; WEST, D. C.; THARP, M. L.; UHL, C. Long-term chronosequence of forest succession in the Upper Rio Negro of Colombia and Venezuela. Journal of Ecology, n. 76, p. 938-958, 1988.

STEININGER, M .K. Secondary forest structure and biomass following short and extended land-use in central and southern Amazonia. Journal of Tropical Ecology, n. 16, p. 689-708, 2000.

SWAINE, M. D.; LIEBERMAN, D.; PUTZ, F. E. The dynamics of tree populations in tropical forest: a review. Journal of Tropical Ecology, n. 3, p. 359-366, 1987.

TENÓRIO, A. R. DE M.; GRAÇA, J. J. DE C.; GÓES, J. E. M.; MENDEZ, J. G. R.; GAMA, J. R. M. F.; SILVA, P. R. O. DA; CHAGAS, P. S. M. DAS; SILVA, R. N. P. DA; MÉRICO, R. R.; PEREIRA, W. L. M. Mapeamento dos Solos da Estação de Piscicultura de Castanhal, PA. Belém: FCAP, 1999. p. 5-26. (Informe Técnico, 25)

TUCKER, J. M.; BRONDIZIO, E. S.; MORAN, E. F. Rates of forest regrowth in eastern Amazonia: a comparison of Altamira and Bragantina Regions, Pará State, Brazil. Interciencia, v. 23, n. 2, p. 1-10, 1998.

UHL, C. Factors controlling succession following slash-and-burn agriculture in Amazonia. Journal of Ecology, n. 75 , p. 377-407, 1987.

UHL, C.; JORDAN, C. F. Succession and nutrient dynamics following forest cutting and burning in Amazonia. Ecology, v. 65, n. 5, p. 1476-1490, 1984.

UHL, C., BUSCHBACHER, R; SERRÃO, E. A. S. Abandoned pastures in Eastern Amazonia. I. Patterns of plant succession. Journal of Ecology, n. 76, p. 663-681, 1988.

VIEIRA, I. C. G. Forest Succession after Shifting Cultivation in Eastern Amazonia. Scotland: 1996. Thesis (Ph.D) - University of Stirling, 1996.

WHITMORE, T. C. A introduction to tropical rain forest. Oxford: Clarendon Press, 1990. 226p.

ZWETSLOOT, H. Forest succession on a deforested area in Suriname. Turrialba, n. 31, p. 369-379, 1981. 